\section{TOCQUEVILLE Y EL LAICISMO EN AMÉRICA}

\author{
Antonio Hermosa Andújar
}

Universidad de Sevilla

\begin{abstract}
We have only afforded the political -not the culturalaspect of the laicism although Tocqueville clearly supported both aspects. When approaching the religious fact, the author of the work The Democracy in America is not interested in the theological dimension but merely in the social one. The religion plays a stabilization role whether in the day life of each person or in the community life. In fact, its irruption in the public life takes place, when the main causes are analyzed, and, among other points, it is considered necessary to preserve the democratic republic. Its crucial importance was previously suggested when listing the quick list of people which it affects and it is enhanced when it becomes evident that its influence covers both the field of the thinking and the field of the action: this will be analyzed subsequently. Anyway, in our critical consideration, we have focussed not only in the confinement of the women in their homes according to the religious doctrine or in the expulsion of the atheists from the kingdom of the humanity because identified and considered as a devil sons -in the American society, a so religious kingdom- but also in the function of the religion as a counterpoint to the passion of the welfare which can be ruled with a minimum of success.
\end{abstract}

KEY WORDS: Tocqueville; laicism; secularization; religion; equality; freedom; democracy; America.

\section{INTRODUCCIÓN}

A la hora de desentrañar la actualidad de Tocqueville quizá se debería comenzar por los grandes tópoi que han hecho del eximio pensador francés uno de los más representativos iconos del pensamiento político de todos los tiempos. 0 quizá cabría adoptar una perspectiva más historicista y dejarnos guiar en nuestro elenco por los diversos usos que los sucesivos períodos históricos han ido haciendo de sus ideas. Este punto de vista es sin duda más reductivo que el primero, pero antes o después nos las habríamos visto con el rechazo del totalitarismo y el sacrificio de la libertad individual que ejecuta, o con la denuncia de los peligros de la sociedad de consumo, que oficia idéntico sacrificio mediante otro ritual, arrancando a sus víctimas el corazón de la libertad en el altar del bienestar.

\section{TOCQUEVILLE AND THE LAICISM IN AMERICA}

RESUMEN: En este trabajo abordamos sólo la dimensión política del laicismo - no la cultural-, bien que Tocqueville fuera partidario destacado de ambas manifestaciones. Al abordar el hecho religioso, el autor de La democracia en América no se interesa en su dimensión teológica, sino en la puramente social. La religión juega aquí un papel estabilizador, tanto en la vida del individuo como en la de la comunidad. De hecho, su irrupción en la vida pública tiene lugar cuando se analizan las "causas principales", entre las que se enumera, que preservan la república democrática. Su crucial importancia, ya insinuada en el rápido elenco de sujetos sobre los que actúa, se realza cuando se constata que su influencia abarca tanto el ámbito del pensamiento como el de la acción. Es eso lo que se analizará a continuación. Ahora bien, en nuestra crítica no sólo ponemos de manifiesto el supuesto de la confinación de la mujer al interior del hogar, exigido por su doctrina, o la expulsión del ateo del reino de la humanidad, al ser identificado como un vástago del demonio en un reino tan religioso como el de la sociedad americana, sino, igualmente, que la función de la religión como contrapunto a la pasión del bienestar pueda ser llevada con un mínimo de éxito.

PALABRAS CLAVE: Tocqueville; laicismo; secularización; religión; igualdad; libertad; democracia; América.

Habrían sido ésas, ocasiones para ensalzar su alegato contra la tiranía de la mayoría, ese burdo ser moral igualitario que ya Madison denunciara en El Federalista con argumentos símiles ${ }^{1}$ a los de su heredero, susceptible de ser agitado como un espantajo autoritario contra minorías y élites, que muestra, además, una apetencia inaudita y constante por establecer un control popular extremo de las instituciones, pero dejando descontrolado al controlador; o bien su alegato contra el "burocratismo estéril", como le llama con cierta pueril ingenuidad André Jardin, cuyos argumentos hemos resumido parcialmente y ampliado aquí ${ }^{2}$, que se establece donde la pasión por los oropeles de la vida privada transfiere el debate racional de las decisiones a la nuda voluntad del nuevo señor de la arena política. Como habrían sido ocasión para enfatizar ese más libertad como paliativo a los males producidos por la misma libertad enarbolada por uno de sus amantes más acérrimos y que, entre todas las opciones del hombre, fue la que más amó3 
una idea que debiera convertirse en lema de estos oscuros tiempos de confusión y cobardía, de miedo e indiferencia; tiempos también, por si fuera poco, de concesiones permanentes que, en aras de supuestas alianzas civilizatorias y de la fingida paz que reportan, acorralan cada vez más la capacidad de acción del hombre y entregan la defensa de la libertad a algunos de sus enemigos naturales. Se diría, una vez más, que el profeta atinó en su afirmación de que las democracias prefieren la igualdad a la libertad, al punto de convertirla en profecía.

Con todo, la visión tocquevilliana del laicismo no deja de ser de interés. Si en su análisis descubrimos que aún nos es útil, eso que hemos ganado intelectualmente; si, por el contrario, el mismo nos revela, de una doctrina que recoge como pocas hasta entonces los datos del problema, su inutilidad, aún nos valdría en otro orden de cosas, pues comprobaríamos que la "nueva ciencia política"4 reclamada por el pensador francés al objeto de hacer más inteligibles los fenómenos sociopolíticos del nuevo mundo y de la época en general, ha sido ya superada por los nuestros, que requieren de otra más matizada, profunda y radical si hemos de entender lo que hacemos, como pedía Hannah Arendt 5 .

\section{LA DOCTRINA DE TOCQUEVILLE}

El laicismo, como se sabe, constituye una de las manifestaciones visibles del proceso moderno de secularización, si bien sus raíces se hunden hasta el siglo VI de nuestra era. Se trata de un fenómeno a la vez cultural y político, en virtud del cual, por un lado, las ciencias y el pensamiento en general se emancipan de toda tutela religiosa para buscar una explicación inmanente de las cosas; Weber lo llamó "desencantamiento del mundo", y constituye su dimensión cultural. De otro, comporta la separación entre Iglesia y Estado, declarando autónomas ambas esferas, que afirman por separado su jurisdicción. Es el laicismo político, el único que en adelante tendremos en cuenta y que centra por completo la atención de Tocqueville.

Al abordar el hecho religioso, el autor de La democracia en América no se interesa en su dimensión teológica, sino en la puramente social. La religión es aquí un factor estabilizador, tanto en la vida del individuo como en la de la comunidad. De hecho, su irrupción en la vida pública tiene lugar cuando se analizan las "causas principales", entre las que se enumera, que preservan la república democrática. Su crucial importancia, ya insinuada en el rápido elenco de sujetos sobre los que actúa, se realza cuando se constata que su influencia abarca tanto el ámbito del pensamiento como el de la acción. Es lo que analizaremos a continuación, entre otras razones porque el laicismo se hace presente en medio de ese tráfico de influencias.

Sobre la política, en efecto, ejerce lo que Tocqueville llama una "influencia directa". En Estados Unidos, la religión es una "institución política" que favorece el régimen republicano desde sus orígenes y lo sigue consolidando aún; a lo primero contribuyeron los protestantes, a lo último se han sumado los católicos. Aquéllos, sus primeros habitantes europeos, se habian emancipado de la autoridad del papa ya antes de llegar alli y no la sustituyeron por ninguna otra, sino que prefirieron su propio autogobierno; de ahí, como señala Tocqueville, que su aporte al nuevo mundo consista en un cristianismo perfectamente definible como "democrático y republicano" -vale decir, la autonomía republicana era fecundada por la religiosa.

Los católicos, por su parte, no defendían la democracia con las mismas armas, dado que viven en una especie de "monarquia absoluta"7 y mantienen el orden piramidal con el ardor de su culto y el celo de sus prácticas. No es pues la autonomía personal lo que potencia, sino la más estricta obediencia; pero no es ahí donde el catolicismo juega sus bazas en la democracia, sino en otros ámbitos, como el de su organización y sus dogmas de un lado, y, más coyunturalmente, el de la posición social de los católicos.

Desde un punto de vista organizativo, nos dice Tocqueville, el catolicismo reúne a un sacerdote y a su pueblo, aquél en un plano y éste en otro, cierto: mas en el interior del pueblo de fieles no caben diferencias, por extrema que sea la diversidad personal de sus miembros respecto de su posición social, inteligencia, educación, poder, riqueza, etc. Y otro tanto ocurre desde el punto de vista dogmático, pues todo el mar de distinciones que separa a los creyentes como individuos queda anegado ante los pocos y simples dogmas que les aúnan como fieles: hombre o mujer, ignorante o sabio, noble o plebeyo, todos deben creer lo mismo. Rubrica Tocqueville: el cristianismo, "al aplicar a cada ser humano la misma medida, ama con- 
fundir todas las clases de la sociedad al pie del mismo altar, del mismo modo que están confundidas ante los ojos de Dios" ${ }^{\prime \prime}$. El resultado, pues, es el mismo: la democracia sale doblemente fortalecida en Estados Unidos por cuanto ambas propiedades del cristianismo potencian la igualdad de condiciones que la caracteriza (o con la que a veces sin más se la identifica).

Por último, y desde un punto de vista sociológico, los católicos son hoy menos y más pobres que los protestantes. Su deseo de gobernar sólo puede satisfacerlo el régimen que respete a las minorias y que en los individuos cuente su condición de individuos, no su número, su riqueza... o su religión. Sólo cuando todos gobiernan, ellos gobiernan. Sólo entonces sus necesidades e intereses entran en la agenda pública y sus opiniones contribuyen a determinarla. La participación en el gobierno es la mejor credencial de la legitimidad del régimen, y la pasión de los católicos por la democracia el juicio más firme posible sobre ella. Se explica así la paradoja de que el apestado de la política europea sea al otro lado del Atlántico su más celoso defensor, de que el perseguido en Europa por la libertad haya devenido en América su más abnegado caballero.

Elucidar la paradoja tiene otro significado de suma relevancia. Tocqueville quiere con ello poner de relieve que el catolicismo no es un cuerpo políticamente extraño o, peor aún, naturalmente antidemocrático. Sus instintos, como hubiera podido decir, le son más bien connaturales, según acabamos de comprobar. La norma de su persecución en la Europa moderna es sólo norma europea y su contravención normal en América demuestra que también en la propia Europa podrá convertirse en excepción o, simplemente, desaparecer. Un cambio de contexto ha revelado un nuevo principio de socialidad en materia de religión vinculado al catolicismo; ha bastado un mero cambio de geografía para invalidar toda una historia. 0 mejor: la doble historia de un mismo sujeto. Porque no sólo ha hecho ver el error óptico surgido al mirar el catolicismo como antidemocrático, sino que, de paso, ha anulado la lección medieval, que tanto daño le ha hecho y que está incluso en el origen de sus persecuciones modernas, de que el catolicismo es una religión vinculada al Estado, una religión de Estado consagrada a crear entre los débiles esperanzas de justicia celeste en compensación de su apuesta por justificar las injusticias de sus poderosos aliados terrestres.
La influencia de la religión en la sociedad (americana9), pese a ser "indirecta"10, es aún más poderosa que la inmediatamente ejercida sobre la política. Dicha sociedad es inimaginable sin religión, y en todo caso sus miembros no se imaginan sin ella. Tal es, piensa Tocqueville, su ventaja, como el hecho de constituir la sociedad "más ilustrada y más libre" del mundo moderno, gracias precisamente al imperio ejercido por aquélla sobre sus corazones, es su consecuencia. Añadamos que para una sociedad cualquiera lo importante no es profesar la religión verdadera, algo vital en cambio para cada individuo particular, sino poseer una religión cualquiera: la salvación, en efecto, es asunto personal. Añadamos además, pero cerniéndonos ya a la sociedad americana, que el creyente posee un amplio abanico de sectas donde elegir, lo que le simplifica la tarea. $Y$ añadamos, por último, que si bien las sectas son muchas la religión es una, pues todos se dicen cristianos y la moral cristiana es una y la misma en todas ellas: lo que le facilita la tarea aún más, y con ello la posibilidad de entenderse con sus semejantes"

Ese imperio, dijimos, no se refleja directamente en las leyes del Estado o "en el detalle" de las opiniones de los ciudadanos, pero llega hasta ahí a través de las costumbres; no a través del poder político de los pastores, sino más bien desde el poder sentimental de la mujer: es el hogar, nos dice Tocqueville, el núcleo originario de esa gran severidad de costumbres difundida a lo largo y ancho de la sociedad americana, y en él la mujer reina. Frente al varón, incapaz de ceder al imperativo religioso el control de sus pasiones, la mujer llena con él su alma, "y es la mujer quien hace las costumbres". De ahí, de ella, parte la austeridad moral americana a la conquista de la sociedad y la política, y el buen analista es quien descubre tras los elementos de regularidad y orden en esferas tan activas, y de suyo tan proclives a lo contrario, la santidad del matrimonio.

En ese viaje, las costumbres no están solas. La religión ha hecho asimismo pie en la "inteligencia". La fe religiosa y la fe en la hipocresía, es decir, la fe en la apariencia religiosa, se concitan para crear un mundo sólido y regular en el que creer, y con el que salen ya pertrechados a la escena política. En ésta parece dominar el aire del momento y los fines de los individuos semejan veletas movidas por él. Pero antes de cambiar por cambiar, las certezas de las creencias le hacen oír su voz oracular repitiéndole en una nueva Delfos el recuerda que eres mortal con el que deben

ARBOR Vol. 187750 julio-agosto [2011] 715-724 ISSN: 0210-1963

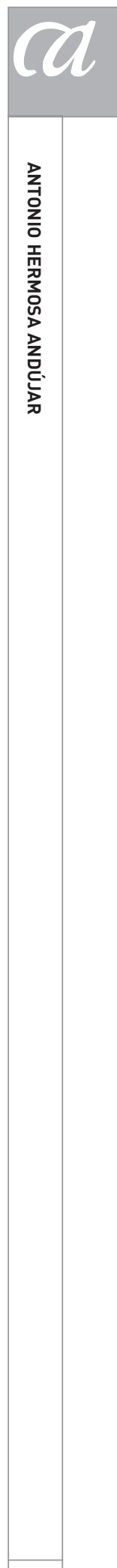

717 
calibrar lo nuevo, medir su valor por el respeto guardado "a la moral y la equidad cristianas". De otro modo: la religión instala en la conciencia del individuo la noción de límite, tanto más valiosa cuanto en el sujeto individual la pasión por el bienestar es infinita y ni cesa siquiera cuando ya se goza; y al sujeto colectivo la ley no se los pone: será, pues, la religión la que vigile su imaginación y su voluntad, y la que le impida, pudiendo legalmente todo, concebir intelectualmente todo e intentar moralmente todo.

La noción de límite define en general la distancia entre el

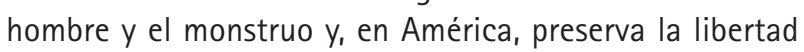
en el hombre. Cuando un fin posible no es pensable 0 deseable el problema de la licitud del conjunto de medios que contribuyen a su obtención se desvanece por sí mismo, y con él el cortejo de irracionalidad que siempre le acompaña. En la práctica los efectos son aún más positivos, pues al quedar sin prender la mecha del odio, el incendio de violencia subsiguiente, que recurre a la libertad para extenderse y requiere de tiranía para apagarse, tampoco tiene lugar. Nadie en América, pues, sigue al revolucionario europeo cuyo programa se resume en la fórmula "todo está permitido en interés de la sociedad". Tocqueville había comentado al respecto que se trata de una "máxima impía que parece haber sido inventada en un siglo de libertad para legitimar a todos los tiranos por venir"12.

Justo por todo ello, compendia, la religión es reconocida por los americanos como "la primera de las instituciones políticas" de su sociedad, y agrega que si bien no da a ninguno de sus miembros algo en realidad innato, el gusto por la libertad, sí "le facilita su uso de manera singular".

También para el individuo la religión era un auxilio vital. La vida, en efecto, es inimaginable sin creencias (religiosas, básicamente) y, para un sujeto libre, añade el genio francés, imposible sin ellas. Primero, porque en el origen de la mayoría de nuestras acciones hay una semilla en forma de creencia sobre Dios y la naturaleza humana; luego, porque cuando a un pueblo le falta el universo religioso contenido en dicha semilla, los individuos se agitan en la zozobra provocada por la duda y el azar, y la impotencia es el lugar donde confluyen sus esfuerzos. Hasta tal punto esto es así, hasta tal punto la visión de la anarquía religiosa es tan intolerable para el hombre como la anarquía política, que Tocqueville sentencia: "si no tiene fe, es menester que sirva, y si es libre, que crea"13.

Se requieren por tanto creencias firmes acerca de Dios tanto como de los deberes de los hombres para con él y de éstos entre sí. Sólo que la condición, trágica siempre y circunstancialmente paradójica, del hombre dificulta la satisfacción del fin apenas señalado. Por una parte, sólo unos pocos privilegiados disponen del tiempo o la inteligencia suficiente para hacerse ideas cabales sobre tales objetos, dada su complejidad intrínseca; por la otra, la necesidad del homo democraticus de semejantes ideas para sus prácticas resultan obstaculizadas por esas mismas prácticas, un torbellino en el que resulta tan fácil entrar como difícil salir. Y la religión, naturalmente, será el remedio a esa conjunción de adversidades. Si bien, para ello, deberá democratizarse, esto es, adaptarse en parte al nuevo sujeto.

¿Qué significa eso? En el universo democrático, la igualdad que lo define produce efectos contradictorios, intangibles en parte para la propia religión, que ésta debe procurar conciliar si no quiere que el individuo se le escape de su reino. En un lado están los que, por así decir, deifican a la masa, el sujeto político que juntos conforman, al punto de hacer de la mayoría una fuente de creencias terrenales que deben ser respetadas cuando no son impías. Tocqueville lo expresa así: "En los siglos de igualdad... es siempre la mayoría la que hace creer; así pues, se la ha de complacer en todo cuanto no sea contrario a la fe"14. En el otro lado están, tanto el sentimiento de independencia que la confianza en uno mismo propicia en su relación con los demás, como la ya mentada pasión por la igualdad, que transforma de manera paulatina a la sociedad en un agregado de mónadas, una yuxtaposición de fortalezas individuales en las que cada sujeto ahoga en la vorágine de sus deseos las exigencias de sus deberes y blinda sus posiciones frente a los demás.

En la lucha por hacer realidad sus objetivos la religión urde diversos tipos de planes. En primer lugar, cuando se presenta solitaria en la arena frente a la masa, el gladiador no cede un ápice en su dogma, que quiere preservar inmaculado, como corresponde a toda religión digna de tal nombre. Pero sí se aviene a simplificar el ropaje con el que adorar al único y verdadero Dios. Con ritos mucho menos sofisticados, con cultos más sencillos intenta penetrar en 
la masa y hablarle de sus problemas, de sus intereses, corrigiéndola desde dentro, purificándola, reivindicando el valor del mundo en el que vive aunque sea un lugar secundario respecto del más allá que espera a sus miembros. Pero no intenta guiarles al detalle, dirigir todos y cada uno de sus movimientos, juntar política y religión, y ésa es, piensa Tocqueville, la ventaja esencial del cristianismo frente al islamismo y la razón insuperable de por qué el Islam carece de futuro democrático (II, p. 40).

Una segunda estrategia adoptada por la religión es la de unirse al sistema moral practicado por la sociedad norteamericana al objeto de combatir el feroz "individualismo" que la aqueja, esto es, "la doctrina del interés bien entendido". En cuanto doctrina ética no es precisamente un dechado de virtudes en sí misma, pues no es mediante la voluntad como se accede al reino de la virtud; pero en cuanto doctrina ética democrática constituye una auténtica filigrana moral, pues cumple dicho objetivo a través del rodeo de las costumbres. Tocqueville llega a considerarla "la más poderosa garantía que les queda frente a sí mismos" a los demócratas estadounidenses (II, p. 176). No, desde luego, transformándolos en místicos o anacoretas, no exigiéndoles gravosos sacrificios con los que violentar sus instintos; ninguna Ifigenia tendrá que reprochar a la diosa que la haya sacado contra su voluntad de los suyos y la fuerce permanentemente a mirar hacia la otra orilla "das Land der Griechen mit der Seele suchend"15 para ser feliz. Pero sí habrá sacrificios, aunque sean pequeños, y en ellos la voluntad oficiará de sumo sacerdote cuando, en nombre del interés general, renuncie a parte del interés privado, es decir, cuando, al obrar de ese modo -signo de un sujeto dueño de sí mismo-, el interés particular garantice la moral colectiva al frenar el deseo particular de acumular más, una pasión inextinguible que, de esa forma, se revela al menos domesticable.

La religión, en tal caso, reforzará semejante doctrina prometiendo al sujeto recompensar en el mundo por venir buena parte de los sacrificios dejados sin premio en el presente, por lo que le hace más llevadera la tarea de obtener una felicidad perdurable al coste de renunciar de continuo a ciertos goces pasajeros. El cristianismo también aquí mostrará su plasticidad para amoldarse a las situaciones, pues su mandamiento de preferir al otro sobre uno mismo lo funda en "el amor de Dios"16, nos dice Tocqueville, lo que permite al cristianismo adivinar en el orden la finalidad de Dios, y asociarse libremente a la misma depurando de las pasiones el plus que lo transgreden; para los americanos, que por si fuera poco no sólo consideran legítimo su bienestar material, sino contar aún más con la felicidad ultraterrena, un ideario así no sólo colma sus aspiraciones éticas, sino que es la ocasión de mostrar la unicidad de su conducta, ya que el goce material se halla vinculado a las asociaciones que lo producen, y a la libertad que lo facili$\mathrm{ta}^{17}$. Gracias a la religión, en suma, el individuo preserva el mismo tenso equilibrio, propio de la libertad, en el ámbito de la moral entre interés privado e interés general, entre deseo y deber, que ya pusiera en práctica como miembro del soberano en la política, respetando aquí como allí la noción de límite.

La religión, por último, consolida su obra ejerciendo sobre el sujeto un poder que ya poseía, un poder que deroga cada domingo el imperio que la pasión por el bienestar ejerce sobre su voluntad los demás días. Un día a la semana el mundo americano deja de rodar para recobrar el sentido y la armonía invisibles en los demás. Tocqueville lo considera connatural a los americanos e invoca esa necesidad de "moralizar su democracia por la religión"18 como postrer testigo de su irremplazable utilidad en el nuevo mundo, tanto a nivel individual como colectivo. Se diría que, merced a esta gesta dominical de pura espiritualidad, la religión compensa a los individuos del peligro que corren de degradarse moralmente a sí mismos al tiempo que mejoran técnicamente las cosas alrededor suyo en aras de su bienestar material.

Si, constatada la influencia ejercida por la religión sobre la sociedad americana, trazada la aureola de beneficios reportados a los americanos tanto a título personal como en su vida social y política; si, comprobado que muchos de esos beneficios la religión los saca de sí misma y otros más del sistema político americano, si nos preguntáramos por si es posible una política sin religión, la respuesta caería por sí sola: la pregunta es, siempre, un mero ejercicio retórico y, en América, un ejercicio retórico inmoral. El solo planteamiento de la supresión de la causa que da continuidad al americano desde su vida en el hogar hasta su participación política, pasando por la variedad y riqueza de manifestaciones sociales, constituiría un impío ejercicio de vanidad intelectual en el que la libertad ha sido cruelmente separada por el retórico de la responsabilidad. Cancelar de su vida el arte que limita, a solas o junto a

ARBOR Vol. $187 \quad 750$ julio-agosto [2011] 715-724 ISSN: 0210-1963

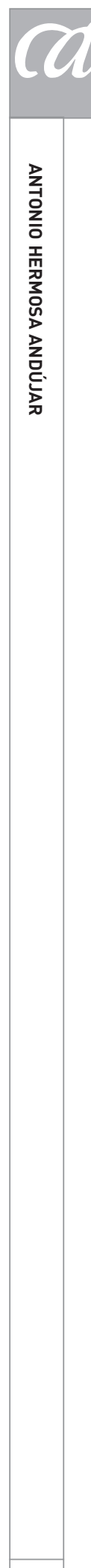

719 
otros, sus acciones reales cuando es infinito el horizonte de los ideales; que intercepta mediante principios la espiral incontenible de sus deseos; que regulariza el desorden connatural a la actividad pública, y da estabilidad y sentido al mundo volátil y confuso de las pasiones; cancelar eso, decimos, sólo es interpretable como veleidad de enemigo: sólo el amante de la tiranía puede pensarlo $y$, en alarde de perversidad, desearlo. "La fe es el estado permanente del hombre", aduce Tocqueville, en tanto "la incredulidad es un accidente" ${ }^{\prime 1}$. En América la historia se ha vuelto contra sí misma, contra su versión europea, y recuperado al fin la naturalidad, vale decir: "el espíritu de religión" y "el espiritu de libertad" caminan juntos nuevamente, pero no "en sentido contrario", como en Europa, sino en la misma dirección ${ }^{20}$. Novalis, que en 1799 escribió que "nur die Religion kann Europa wieder aufwecken und die Völker sichern"21 habria contemplado con satisfacción ese espectáculo de resurrección europea en América.

Lo más notable, con todo, a la hora de evaluar la influencia de la religión en la sociedad americana y buscar su causa nos conduce, según el politólogo francés, muy lejos de donde pretendía el poeta alemán, a saber: al núcleo del laicismo, "a la completa separación de Iglesia y Estado"22, a erigir, como clamara en su día Jefferson, "un muro de separación entre la Iglesia y el Estado"23. Ninguna confesión religiosa es reconocida por la Constitución ni elevada a los altares de la vida pública, ninguna iglesia ha logrado acceso al rango de institución política; sus funcionarios no militan a favor de ningún partido, no ostentan ningún cargo público, sino que se atrincheran en sus púlpitos, tras las paredes de sus lugares de culto. Luchan por mantener suya el alma de los americanos, pero ni siquiera pretenden, ni les sería posible lograrlo si lo intentaran al tener a la opinión en contra, inmiscuirse en los movimientos de sus cuerpos. Cada una, religión y política, a lo suyo, y el americano a las dos. Laicismo en lugar de Estado confesional es el secreto del poder de la religión en América: la causa que, pese a no ser tan directo como en algunos países europeos, la hace mucho más poderosa y efectiva que en ellos.

\section{Critica a Tocoueville}

La religión es la otra cara de la medalla de la libertad, hemos oído decir a Tocqueville, una institución funcional a la República. Con todo, vale la pena echar una nueva ojeada de conjunto a los supuestos, a ciertas prácticas y a las posibles consecuencias de semejante doctrina al objeto de cerciorarnos de que puede pasar por ciencia en lugar de esfumarse como una voluta más de creencias.

Comencemos por la base, por donde todo empieza: por el hogar. Allí la religión apuntalaba el matrimonio haciéndose fuerte en la mujer: era a través de ella como forjaba las costumbres de una sociedad que hubiera fenecido de vértigo sin ella. Y el fruto era tan sólido, tan infranqueable, que el movimiento sin tregua de la sociedad cesaba ante el umbral de la casa, donde todo era recogimiento, respeto, amor y paz.

¿Era realmente pensable que el hogar constituyera por siempre una barrera ante la cual la pasión detuviera su orgía de deseos y sus vehementes consecuencias; una prohibición para el movimiento que todo lo trastoca en las demás esferas de la sociedad, cambiando las riquezas de dueño, a ricos y pobres de sitio, o el poder de manos, etc.? Mejor aún, ¿era concebible pensar que cejara la igualdad $-y$, en este caso, también la libertad- ante un límite habiéndolos rebasados todos desde su nacimiento? Porque, no se olvide, el supuesto de semejante doctrina, que hace del hogar el más allá del más acá, es que la mujer permanecerá por siempre relegada en su interior, que ése es su lugar social natural del que no debe moverse, que no es apta para otras tareas sociales; el que, en compensación, contrapesará su minusvalía social y jurídica con un asiento fijo a la diestra del dios de la moral. Lo que vino después habla por sí solo.

El supuesto se desmoronó con el tiempo y si la lógica de Tocqueville hubiera sido buena, caida la base se habria derrumbado el resto del edificio. Todas sus reconocidas cualidades proféticas quedaron, cierto, pétreamente encantadas ante tal supuesto; empero, el sortilegio habria seguido surtiendo efectos si, pudiendo ver el futuro, hubiera gozado de la ocasión de constatar que el trastocamiento de la familia, si bien está en las raíces de una mayor laicización de la sociedad, de una mayor apertura en las costumbres, no puso fin a la religión; y, sobre todo, aumentó el grado y prodigó a nuevos sujetos el bien de la libertad al extender también el de la igualdad real a la otra mitad de la población. Habría comprobado hasta qué punto en ciertos individuos los intereses alían la religión 
con sus supuestos enemigos en un totum revolutum tan productivo como impío en sus objetivos; cómo su antídoto contra la pasión del bienestar produce menos efectos de los deseados, y cómo, en definitiva, la correlación establecida entre religión y libertad, lejos de ser un axioma, adquiría la vitola de la mera creencia.

La fe es el estado permanente del hombre y sería siempre un hecho del alma del americano medio, nos decía también. No tenemos por qué saltar hacia el futuro, como en el caso anterior, para mencionar algunas de las consecuencias en el presente, que el propio Tocqueville menciona. La fe es algo tan extendido, tan, insistamos, natural y común, tan americano, casi cabría decir, que, justo por eso, el ateo es convertido en el negro de la mo$\mathrm{ral}^{24}$, es decir, ese personaje eternamente enclaustrado en el gueto del desprecio y de la marginación: en realidad, situado más allá del nivel de lo humano -como el negro más allá de la política-, pues su palabra no es creída por el juez, su doctrina declarada enemiga jurada de la sociedad por el, en general, genial observador de la misma, y su vida arrojada a orillas de la igualdad del rebaño por la piadosa oveja estándar, tan celosa ella de su religión ${ }^{25}$. La consecuencia es que, si bien Tocqueville consideraba funcional la religión para la libertad ${ }^{26}$ - una verdad a medias en el mejor de los casos, según aludimos más arriba-, también lo es, y con total certeza, su contrario: la religión es funcional a la discriminación y persecución de quienes no profesan su $\mathrm{fe}^{27}$.

La religión como contrapunto de la pasión por la igualdad no sólo formaba parte de su bondad, sino que constituía otro dato descontado más. Entre ella y la doctrina del interés bien entendido recomponían los destrozos introducidos por esa pasión inmortal, la passion mère la llama Tocqueville, en el seno de la sociedad desde el corazón de sus miembros. Pero la religión, por su parte, aportaba la garantía de éxito en un combate en el que aquella doctrina, por sí sola, malbarataba sus fuerzas. Formaba parte de su primacía en la sociedad.

Naturalmente, la religión saca todo ese poder del lugar de privilegio que ocupa en la modelación de las costumbres. Ahora bien, ¿se trata de un poder real, de un desideratum o de otra cosa? Pregunta semejante, cierto, parece más venganza de algún ateo materialista que duda seria. Miremos, no obstante, con detenimiento a los contendientes.
De un lado, un deseo irresistible en acción permanente; de otro, un sacrificio llevadero, pero igualmente constante, recompensado, ahora sí y ahora no, cuya misión no es sino la de justificar la acción del deseo; por último, un más allá que suple el mal regusto moral dejado por la falta de recompensa, y que más que por sí mismo, por el destino que promete, interesa en general por su ayuda aquí y ahora, es decir, en el ámbito sin tregua dominado por el deseo. Juntos, remarca el político francés, funcionan como una máquina bien engrasada, pero dada la fuerza ejercida por cada uno sobre la voluntad, ¿cabe pensar que habrá siempre armonía? ¿No es más fácil pensar que la cadena se romperá en todos por el lado más frágil y que éste, salvo alguna innatural excepción, nunca será el de la pasión del bienestar?

Hasta cabría ser más irreligioso todavía y preguntar: puesto que el ciudadano común sabe que tiene el domingo para espiritualizarse, ¿no servirá eso precisamente de acicate para materializarse el resto de la semana? Si el domingo se me perdonan oficialmente todos mis pecados, ¿por qué no seguir cultivándolos entre fiestas, cuando tanta abundancia de bienes proporcionan? La rutina de esa abundancia sería una señal divina de que lo hago bien a los ojos de Dios, podría pensar más de uno, y, en cualquier caso, la ritualización semanal del perdón me excusa formalmente del arrepentimiento, o, mejor, del "vicio del remordimiento", como le dice Dorotea a Juan Preciado en Pedro Páramo, la genial obra de Juan Rulfo.

Tampoco aquí es preciso recurrir a lo que sucedió después para desmentir a Tocqueville. Pero lo cierto es que el sentimiento religioso ha decaido aun cuando siga siendo fuerte ${ }^{28}$, la pasión por el bienestar no y la libertad, aumentada, ha perdurado, pese al paréntesis de la guerra de Iraq en lo concerniente a la libertad de prensa y a la deriva iliberal emprendida hace décadas, sobre la que nos ilumina y previene Sheldon Wolin ${ }^{29}$. Quizá la guerra que aquélla introducía en la sociedad no era a fin de cuentas tan destructiva o quizá el sujeto y la sociedad inventan antídotos aun sin saberlo; pero lo cierto es que el sansón religioso es mucho menos fuerte de lo afirmado, porque el reino de sus efectos ha tenido que repartirlo con su principal enemigo externo, el ateísmo, además de con otros factores más, y porque posee un peculiar demonio interior que rebaja sus pretensiones de grandeza.

ARBOR Vol. 187750 julio-agosto [2011] 715-724 ISSN: 0210-1963 
La religión, nos decía Tocqueville, influyendo directamente sobre el individuo y la política, impedía en aquél que la duda y el azar -el debe de todo individuo en un mundo igualitario- corroyeran el firme universo de las creencias y lo diluyeran en un caos de impotencia, y reforzaba en ésta la autonomía y la igualdad republicanas. E influyendo indirectamente en la sociedad, la untaba de orden y regularidad, y por su través la idea de límite. Kant hubiera podido decir aqui que el Grenzgott de la moral no cede ante el poderoso Júpiter de la anarquía.

Ahora bien, el perpetuo aluvión de deseos que sacude la estabilidad de la sociedad e inocula desazón y temor en el alma de los individuos, en la medida en que delatan falta de civismo y hasta corrupción no son, si se les considera en una óptica religiosa, sino pecados, vale decir, las acciones del yo pecador $u$ hombre religioso en sociedad. Cuando el ciudadano roba y cuando el político prevarica, si son religiosos, están, además, pecando. ¿De qué le ha servido ese mundo de colores pintado por la religión? El pecado, en efecto, es el modo en el que la religión pregona su impotencia frente a la realidad, al punto de desmoronarse por dentro. Sin duda, deja intacto el reconocimiento del poder del Dios de turno, pero sempiternamente tocada su omnipotencia, incapaz, como se advierte, de hacerse dueña del corazón o, al menos, de la voluntad de sus fieles.

En el pecado, cierto, el conflicto se hace personalmente invisible en la caja fuerte de la conciencia moral, y se esfuma por entero tras el muro del arrepentimiento y del perdón protestantes, o de la contrición y la confesión católicas -las diversas figuras de la mala conciencia que no raramente encuentra un lenitivo para el dolor en el cinismo-, urdido en torno a él. Pero se hace perfectamente patente en la secuela colectiva, vale decir, pública, de la parte de ese inframundo constituida por la falta de civismo y la corrupción: monarcas, por cierto, a los que rinden incesante pleitesía tirios y troyanos, gobernantes y gobernados, creyentes y ateos, hombres y mujeres, americanos y foráneos, demócratas o no ${ }^{30}$. En el pecado (como en el delito), la naturaleza humana desafía el poder de la religión para controlarla; su infinita reiteración es ya un juicio acerca de dicho poder.

En otro orden de cosas, cuando se insta a la religión a adaptarse a la democracia para sobrevivir en democracia, no parece que el énfasis recaiga en aquélla, sino en ésta; y cuando se la vitorea por aliarse a la moral del interés bien entendido, prometiendo al renunciante en el más acá, a parte de su interés, salvación eterna en el más allá, ¿no se está estableciendo un do ut des moral en el que la religión compra con la recompensa futura la virtud del sacrificio personal por los otros realizado en el presente? Y si dicho sacrificio se efectúa, pese a la supuesta codicia del sacrificante, a lo infinito de su deseo de bienestar, y pese, además, a lo vaporoso de tan lejana compensación espiritual, ¿no cabria pensar que aquél ha podido advertir, por sí mismo, una necesidad en su acción, la exigencia de una renuncia a quererlo todo para que la sociedad, y él con ella, sobreviva, y que por lo tanto puede hacer lo mismo haciendo a menos de la fatal promesa y de su premio? Por último: ¿no se estaría, en este caso, haciendo uso de la propia autonomía moral cuando se obra sin el chantaje del premio posterior y renegando de la misma cuando se obra con el objeto de ganarlo? Prosiguiendo por esta vía no se tardaría en concluir que sólo el ateo tiene la posibilidad de ser autónomo desde el punto de vista moral, y que sólo el perverso y/o el necio necesitan de la trascendencia -sólo el perverso y/o el necio pueden creer en Dios, pues- para cumplir con sus obligaciones, sean cívicas o religiosas, pues muchas son las mismas consideradas desde dos puntos de vista diferentes. Pero prosiguiendo por esa vía, pronto se entraría también en una historia, la del peso de otros factores de la vida democrática en la conservación de la misma, que aquí y ahora no es la que toca contar. De momento nos conformamos con argumentar que, frente al apostolado religioso de Tocqueville, la democracia americana tenía vida y futuro más allá de la $\mathrm{fe}_{1}$ y con sugerir que al hombre republicano realmente autónomo le sobra la religión. 
1 The Federalist, New York, Random House, 2001, n. ${ }^{\circ} 48$, p. 316. La tentación tiránica de las asambleas representativas democráticas también fue denunciada por Hamilton (.$^{\circ}$ 71, p. 459), quien ya había ilustrado en una entrega anterior acerca de los límites de las democracias helenas (n. ${ }^{\circ}$, p. 47). Son parte de esas auxiliary precautions ("garantías auxiliares") con las que la república, custodiando al custodio, se preserva a sí misma de su principal garantía: el pueblo (n. ${ }^{\circ}$ 51, p. 332). Sobre esto último, véase igualmente el opúsculo de Madison ¿Quiénes son los mejores guardianes de las libertades del pueblo?, de 22 de diciembre de 1792, en el que se contesta de inmediato que "el propio pueblo" (en Madison, República y libertad, Madrid, CEPC, 2005, p. 117).

2 Cf. su Préface a De la Démocratie en I'Amérique (en lo sucesivo DA), Paris, Gallimard, 1986, pp. 7-29.

3 Mi instinto, mis opiniones (en Alexis de Tocqueville, Discursos y Escritos políticos, Madrid, CEPC, 2005), p. 3.

4 DA, Introduction, p. 43. Véanse también el texto final de la edición citada de sus Escritos y Discursos Políticos ("Discurso de apertura en la Academia de Ciencias Morales y Políticas", pp. 161-172) y mi propia introducción, secc. 1.a p. 21.

5 H. Arendt, The Human Condition, Chicago, The University of Chicago Press, 1998, Prologue.

6 Una enjundiosa sintesis de los logros del movimiento secularizador puede verse en R. Porter, The Creation of the Modern World, New York-London,

Recibido: 10 de noviembre de 2010 Aceptado: 1 de marzo de 2011
9 Si bien Tocqueville gusta de afirmaciones de carácter general, ontológicamente válidas para toda sociedad, todas sus referencias resultan aplicables integramente tan solo a la americana. Por eso, salvo especificación ulterior, también nosotros usaremos la misma licencia.

10 DA, I, p. 430.

11 Hoy, como se sabe, el abanico sectario se ha ampliado, pero la existencia de "un dios que trata a todas las personas como si fueran sus hijos y que se preocupa de todas ellas por igual", continúa prevaleciendo como antaño (cf. R. Dworkin, La democracia posible, Barcelona, Paidós, 2008, p. 31).

12 DA, I, p. 433.

13 DA, II, p. 39.

14 DA, II, p. 45.

15 "Buscando con el alma la tierra griega" (Goethe, Iphigenie auf Tauris, Goethes Werke, Leipzig, 1926, B. 7, Acto I, Esc. 1.a).

16 DA, II, p. 179.

17 Véase $D A, I I-2,14$.

18 DA, II, p. 200.

19 DA, I, p. 439.

20 DA, I, p. 437.

21 "Sólo la religión puede despertar a Europa y dar seguridad a los pueblos" (Novalis, "Die Christenheit oder Europa", en Werke, Tagebücher und Briefe Friedrich von Hardenbergs, MünchenWien, 1978, pp. 731-750).

22 DA, I, ibidem.

23 Jefferson, Carta a la asociación bautista de Danbury (Connecticut) (1-11802) (en Autobiografía y otros escritos, Madrid, Tecnos, 1987).

24 Ateo y materialista, además. Pero, quizá, el fervoroso antimaterialista Tocqueville se habria retractado un poco si usando aquí la cabeza en lugar de la fe hubiera calibrado mejor el materialismo, porque en lugar de 
despacharlo sin más habría podido reconocer en algunas afirmaciones de La Mettrie una parte de su herencia (cf. una muestra en su Le Système d'Épicure, secc. XCIII, pp. 256-257 [en La Mettrie, Oeuvres Philosophiques, Vendôme, Coda, 2004]).

25 DA, II, pp. 201-202. No está de más en este punto traer a colación las recientes palabras de R. Dworkin: "Los norteamericanos que creen que pueden reclamar una sociedad religiosa tolerante suponen que una mayoría de ciudadanos, cuya actuación respete el procedimiento político habitual, tiene derecho a usar la ley para configurar el carácter religioso de la cultura que compartimos" (op. cit., p. 100) (cursivas nuestras). Parece, pues, que sin ese celo religioso le iría mejor, o por lo menos padecerían más tolerancia, tanto los ateos como los religiosos que entienden la fe menos por las bravas.

26 Cf. l, p. 436.

27 S. Rodotà, Perché laico, Roma-Bari, Laterza, 2009, p. 21 (cf. también p. 14).

28 En especial, por paradójico que pudiera parecer, en esa América profunda que vota conservador, ama el rifle más que el cine y celebra con reelecciones presidenciales la invasión de otros países en nombre de la democracia y con un ejército en el que el soldado raso difícilmente pertenece a la raza WASP.

29 S. Wolin, Democracia S. A. La democracia dirigida y el fantasma del totalitarismo invertido, Madrid, Katz, 2008.

30 En un tema como éste aún pueden resultar de interés las reflexiones de R. Aron sobre la corrupción en los "regimenes constitucional-pluralistas", entre otras razones porque la religión católica, con su Soberano al frente, no deja de andar por medio, sobre todo en paises como los latinos, en los que su hegemonía moral ha sido indiscutible (cf. Démocratie et totalitarisme, Paris, Gallimard, 2007, sobre todo el cap. IX). 